\title{
Effects of Varenicline on the Reinforcing and Discriminative Stimulus Effects of Cocaine in Rhesus Monkeys
}

\author{
Robert W. Gould, Paul W. Czoty, Susan H. Nader, and Michael A. Nader \\ Departments of Physiology and Pharmacology (R.W.G., P.W.C., S.H.N., M.A.N.) and Radiology (M.A.N.), Wake Forest \\ University School of Medicine, Winston-Salem, North Carolina
}

Received June 28, 2011; accepted August 17, 2011

\begin{abstract}
Varenicline is a low-efficacy, $\alpha 4 \beta 2^{*}$ subtype-selective nicotinic acetylcholine receptor ( $\mathrm{nAChR}$ ) agonist that has shown success in smoking cessation and promise in preclinical assessments relating to other drugs of abuse. The primary goal of the present study was to examine the effects of varenicline on cocaine self-administration and cocaine discrimination and compare these effects with those of the nAChR agonist nicotine and antagonist mecamylamine. One limitation of agonist treatments is the potential for abuse. Thus, a second goal was to examine the abuse potential of varenicline in rhesus monkeys. In the first experiment, rhesus monkeys $(n=3)$ were trained to self-administer cocaine (saline, $0.01-0.56 \mathrm{mg} / \mathrm{kg}$ ) under a progressive-ratio schedule of reinforcement; monkeys also earned all of their food by responding on another lever under a fixedratio 50 schedule of reinforcement. Chronic administration of
\end{abstract}

varenicline $(0.01-0.56 \mathrm{mg} / \mathrm{kg}$ p.o., salt) potentiated the reinforcing effects of cocaine, whereas mecamylamine (0.3-1.7 $\mathrm{mg} / \mathrm{kg}$ p.o, i.m., i.v., salt) had no significant effects on cocaine self-administration up to doses that disrupted food-maintained responding. Neither varenicline $(0.01-0.17 \mathrm{mg} / \mathrm{kg}$, salt) nor nicotine $(0.01-0.1 \mathrm{mg} / \mathrm{kg}$, base) functioned as reinforcers when substituted for cocaine. Finally, in monkeys trained to discriminate self-administered $0.3 \mathrm{mg} / \mathrm{kg}$ cocaine, varenicline $(0.1-0.3$ $\mathrm{mg} / \mathrm{kg}$ i.v.) did not substitute for cocaine but, along with mecamylamine (0.3-1.7 $\mathrm{mg} / \mathrm{kg}$ i.v.) and nicotine (0.03-0.1 $\mathrm{mg} / \mathrm{kg}$ i.v.), potentiated the discriminative stimulus effects of cocaine. These results suggest that varenicline has low abuse liability in monkey models of cocaine abuse, but would not be an effective medication for cocaine addiction.

\section{Introduction}

The effects of cocaine on dopamine (DA) neurotransmission continue to be a primary target for pharmacotherapy development (e.g., Grabowski et al., 2004). More recently, researchers have examined neurotransmitter systems that indirectly modulate DA activity (e.g., Karila et al., 2008). For example, interactions between the acetylcholine (ACh) and DA neurotransmitter systems have implications for drug development to treat addiction (Lester et al., 2010). Consistent with the observation that nicotinic $\mathrm{ACh}$ receptor (nAChR) agonists can increase DA release (Rollema et al., 2007, 2010), nicotine, a high-efficacy agonist that binds nonselectively to

This research was supported by the National Institutes of Health National Institute of Drug Abuse [Grants DA06630, DA12460].

A preliminary account of these data was presented previously: Gould RW Czoty PW, Nader SH, and Nader MA (2009) Effects of varenicline on the reinforcing and discriminative stimulus effects of cocaine in rhesus monkeys, at the 2009 Experimental Biology Meeting; 2009 April 18-22; New Orleans, LA; American Society for Pharmacology and Experimental Therapeutics, Bethesda, MD. FASEB J 23:588.6.

Article, publication date, and citation information can be found at http://jpet.aspetjournals.org.

doi:10.1124/jpet.111.185538 all nAChR subtypes, fully substituted for cocaine in monkeys and rodents (Garza and Johanson, 1983; Desai et al., 2003) and D-methamphetamine in rodents (Desai and Bergman, 2010) in drug discrimination studies. Moreover, nicotine and cocaine combinations resulted in greater self-administration than cocaine alone in monkeys (Freeman and Woolverton, 2009). Conversely, mecamylamine, a noncompetitive antagonist at all nAChR subtypes, selectively attenuated cocaine self-administration in rodents (Levin et al., 2000). In cocainedependent, nontreatment-seeking individuals, acute nicotine enhanced and mecamylamine diminished cue-induced craving for cocaine (Reid et al., 1998,1999). These studies support $\mathrm{nAChR}$ blockade as a mechanism to reduce cocaine-related behaviors.

However, one clinical trial examined a single low dose of mecamylamine in treatment-seeking, cocaine-dependent patients compared with a placebo control group and reported no differences in cocaine intake and rates of abstinence or selfreports of cocaine craving, and severity of dependence was higher in the mecamylamine-treated group (Reid et al., 2005). Increased withdrawal symptoms or negative side effects are common drawbacks associated with an antagonist

ABBREVIATIONS: DA, dopamine; ACh, acetylcholine; $n A C h R$, nicotinic ACh receptor; FR, fixed ratio; PR, progressive ratio; ANOVA, analysis of variance. 
treatment approach and often result in poor compliance (see Grabowski et al., 2004). Therefore, a drug with both agonist and antagonist effects, such as a low-efficacy agonist, may be more successful in reducing craving and drug use than an antagonist alone and possess lower abuse liability than higher-efficacy agonists (for review see Rahman, 2011). In support of this view, mecamylamine-nicotine combinations and low-efficacy $\mathrm{nAChR}$ agonists have been shown to increase rates of abstinence and reduce nicotine craving compared with placebo-controlled groups in smoking cessation trials (Rose et al., 1994; Gonzales et al., 2006).

Varenicline (Chantix), a Food and Drug Administrationapproved medication for smoking cessation, has high affinity (>4000- and 5000-fold compared with $\alpha 3 \beta 4^{*}$ or $\alpha 7^{*}$ ) and potency ( $>24$ - and 8-fold compared with $\alpha 3 \beta 4^{*}$ or $\alpha 7^{*}$ ) at $\alpha 4 \beta 2 *$ nAChRs $(*$ denotes the presence of additional accessory subunits) (Coe et al., 2005; Mihalak et al., 2006). Consistent with a partial agonist profile, in vitro studies showed that varenicline had low efficacy $(\sim 15 \%)$ at $\alpha 4 \beta 2 *$ but high efficacy $(\sim 93$ and $75 \%)$ at $\alpha 3 \beta 4^{*}$ or $\alpha 7^{*}$ receptors compared with the full agonist ACh (Mihalak et al., 2006). In vivo, varenicline elevated DA levels in the nucleus accumbens but to a lesser degree $(\sim 35 \%)$ than nicotine and attenuated nicotine-induced DA release and nicotine self-administration in rodents (Rollema et al., 2007). In clinical trials, varenicline reduced nicotine craving and rates of relapse to cigarette smoking (Gonzales et al., 2006). Varenicline treatment decreased ethanol intake in rodents (Steensland et al., 2007) and alcohol consumption in moderate smokers (McKee et al., 2009). In addition, low doses of varenicline attenuated cueand cocaine-induced reinstatement of cocaine seeking in rodents (Guillem and Peoples, 2010), although in one published trial, varenicline did not affect cocaine use in treatmentseeking individuals (Poling et al., 2010).

In measures of abuse liability, varenicline has been shown to substitute for nicotine in drug discrimination and functioned as a reinforcer when substituted for nicotine on a progressive-ratio (PR) schedule in rats (Rollema et al., 2007). In a reinstatement model in rats previously trained to self-administer cocaine, a high dose of varenicline increased cue-induced reinstatement (Guillem and Peoples, 2010). However, Desai and Bergman (2010) recently found that although nicotine completely substituted for the methamphetamine stimulus, varenicline did not substitute and did not attenuate the discriminative stimulus effects of the training dose of methamphetamine. One goal of the current study was to extend the assessment of abuse liability of varenicline to monkey models of cocaine abuse, using intravenous cocaine self-administration and cocaine discrimination. A second goal was to examine the efficacy of varenicline on cocaine self-administration and cocaine discrimination. For the self-administration studies, a dosing regimen was used in which treatment occurred every day, but access to cocaine was studied only weekly, to better model the human treatment conditions (Czoty et al., 2011). For drug discrimination studies, monkeys selfadministered the drug or vehicle, rather than it being investigator administered (Martelle and Nader, 2009). In most studies, we also compared the effects of varenicline with those of the high-efficacy agonist nicotine and the nonselective antagonist mecamylamine.

\section{Materials and Methods}

\section{Subjects}

Eight adult male rhesus monkeys (Macaca mulatta) served as subjects. All subjects had a history of cocaine self-administration and/or drug discrimination including experimental treatment with various dopaminergic drugs. All were previously surgically implanted with chronic indwelling femoral or jugular catheters that were connected to vascular access ports (Access Technologies, Skokie, IL); surgical procedures have been described previously (Czoty et al., 2006). Five monkeys (R-1268, R-1425, R-1427, R-1429, and R-1526) were involved in drug self-administration studies; all but R-1526 also responded on a lever and earned their daily food in the form of 1-g food pellets (Bio-Serv, Frenchtown, NJ). Three monkeys (R-1524, R-1525, and R-1430) were used in cocaine discrimination studies and, along with R-1526, were fed LabDiet (Richmond, IN) Monkey Chow in addition to food pellets. The total daily ration of pellets was calculated to maintain target weights, determined monthly, at approximately $95 \%$ of free-feeding weights (range 110 185 pellets). When monkeys earned fewer than the requisite number of food pellets, supplementary food (LabDiet Monkey Chow) was given at 7:30 AM to raise the total food intake to the necessary level. Monkeys received fruits or vegetables at least three times per week. Water was available ad libitum. Experimental and enrichment protocols were approved by the Wake Forest University Animal Care and Use Committee. All studies were carried out in accordance with the National Research Council Guidelines for the Care and Use of Mammals in Neuroscience and Behavioral Research (Institute for Laboratory Animal Research, 2003) as adopted by the National Institutes of Health.

\section{Apparatus}

Monkeys were individually housed in sound-attenuating, ventilated cubicles $(91 \times 91 \times 91 \mathrm{~cm}$; Plas Labs, Lansing, MI), which also served as their experimental chamber. The front of each panel was made of clear Plexiglas to allow visual access to other monkeys in the room. Each monkey was fitted with a stainless-steel harness (Restorations Unlimited, Chicago, IL). A metal spring arm (Restorations Unlimited) connected the harness to the back wall of the cubicle. A catheter was connected to an infusion pump outside of the cage, threaded through the spring arm, and connected to a vascular access port via a 22-gauge Huber Point Needle (model PG20-125; Access Technologies). To maintain catheter patency, the catheter was filled with heparinized saline $(100 \mathrm{U} / \mathrm{ml})$ between sessions. Two metal levers (PRL-001; BRS/LVE, Beltsville, MD) were mounted $23 \mathrm{~cm}$ apart on the Plexiglas door with four stimulus lights, alternating white and red, above each lever. In addition, the cubicles of monkeys R-1430, R-1524, and R-1525 (cocaine discrimination study) had a photo-optic switch (Stewart Ergonomics, Furlong, PA) mounted centrally on the door, $\sim 30 \mathrm{~cm}$ above and equidistant between the two response levers. A yellow stimulus light was mounted above the switch. A food-pellet dispenser (G5210, model A; Gerbrands, Arlington, MA) was mounted on the top of the door and connected by tygon tubing to a food receptacle located between the two levers. An infusion pump (Cole-Parmer Instrument Co., Vernon Hills, IL) was located on the top of the chamber to deliver drug solutions intravenously over $10 \mathrm{~s}$ at a rate of approximately $1.5 \mathrm{ml} / 10 \mathrm{~s}$. Self-administration doses were studied by changing the drug concentration delivered intravenously.

\section{Cocaine Self-Administration}

Procedure. For five monkeys, responding on the left lever was maintained by food pellet presentation under a fixed-ratio (FR) 50 schedule and on the right lever by injections of cocaine under a PR schedule (Czoty et al., 2011). Food availability began each morning at 8:00 $\mathrm{AM}$ and lasted $23 \mathrm{~h}$ or until all pellets were received, which under baseline conditions typically occurred within $2 \mathrm{~h}$. Cocaine 
availability under the PR schedule began at 3:00 PM each afternoon and lasted $16 \mathrm{~h}$ or until $2 \mathrm{~h}$ expired during which no injection was received. Thus, after 3:00 PM food and cocaine were concurrently available if all food had not been obtained. The response requirement for each drug injection followed the equation established by Richardson and Roberts (1996): ratio $=\left[5 \mathrm{e}^{(\text {injection } \# \times 0.2)}\right]-5$. The first response requirement corresponded with the 12 th value from the equation (50 responses) and was followed by $62,77,95,117$, etc. Availability of each reinforcer was signified by the illumination of two white lights above the respective lever. Upon completion of a ratio the white lights were extinguished and two red lights above the lever were illuminated for $2 \mathrm{~s}$ (pellet delivery) or $10 \mathrm{~s}$ (drug infusion). A timeout period followed, during which all lights above that lever were extinguished and responding on that lever had no consequences but was recorded; the timeout period lasted $10 \mathrm{~s}$ after pellet delivery or $10 \mathrm{~min}$ after drug delivery. Initially, to determine baseline doseeffect curves, saline and each dose of cocaine $(0.003-0.56 \mathrm{mg} / \mathrm{kg})$ were made available for a minimum of 5 days and until the number of injections received varied less than $20 \%$ from the mean of 3 consecutive days with no apparent trend. For the drug substitution and the subsequent studies involving chronic varenicline or mecamylamine treatment, a cocaine maintenance dose was chosen for each monkey (R-1268, R-1425, 0.1 mg/kg/injection; R-1427, 0.017 mg/kg/ injection; R-1526, $0.03 \mathrm{mg} / \mathrm{kg} /$ injection cocaine) from the ascending limb of the dose-response curve.

Experiment 1: Assessment of the Reinforcing Effects of Varenicline and Nicotine. In three monkeys (R-1268, R-1425, and $\mathrm{R}-1427)$ doses of varenicline dihydrochloride $(0.01-0.17 \mathrm{mg} / \mathrm{kg} / \mathrm{injec}-$ tion, salt) and nicotine bitartrate $(0.01-0.1 \mathrm{mg} / \mathrm{kg} / \mathrm{injection}$, free base) were substituted for the maintenance dose of cocaine for a minimum of five consecutive sessions and until responding was deemed stable according to the aforementioned criteria. Varenicline was tested first in all monkeys, and all doses were tested in random order.

Experiment 2: Effects of Chronic Varenicline and Mecamylamine Treatment on Cocaine- and Food-Maintained Responding. After redetermination of a cocaine dose-response curve, cocaine self-administration sessions were discontinued; food-maintained responding continued to be studied daily. Initially, a low dose of varenicline $(0.03 \mathrm{mg} / \mathrm{kg}$ p.o., salt $)$ was administered once per day approximately $30 \mathrm{~min}$ before food availability began (i.e., 7:30 AM). Seven days later, the maintenance dose of cocaine was made available for one PR self-administration session in the evening. If the number of cocaine injections from this session deviated $( \pm 3$ injections) from the baseline, treatment was maintained at this dose, and a randomly selected cocaine dose $(0.01-0.56 \mathrm{mg} / \mathrm{kg} / \mathrm{injection})$ was tested every third day until the reinforcing strength of each cocaine dose was determined twice in the presence of varenicline. If no effect of treatment was noted after the first test session, the varenicline dose was increased and a PR self-administration session was conducted 7 days later. The first increase in varenicline dose was from once- to twice-daily oral treatment with $0.03 \mathrm{mg} / \mathrm{kg}$ varenicline (7:30 $\mathrm{AM}$ and 5:00 PM). Further increases in varenicline dose were accomplished by maintaining twice-daily administration and increasing the dose in quarter- or half-log increments up to $0.56 \mathrm{mg} / \mathrm{kg}$ b.i.d. All oral dosing was achieved by injecting a small volume of drug into palatable food items (a piece of banana, peanut butter, etc.). In monkeys, the half-life of varenicline is $\sim 24 \mathrm{~h}$ (Obach et al., 2006). Therefore, steady-state plasma levels were attained before initial cocaine self-administration sessions. After the cocaine dose-effect curve had been redetermined during $0.56 \mathrm{mg} / \mathrm{kg}$ varenicline treatment, chronic varenicline treatment was discontinued. Two weeks later, post-treatment cocaine dose-response curves were determined under a similar regimen such that a random dose of cocaine (saline, $0.003-0.56 \mathrm{mg} / \mathrm{kg}$ ) was made available every third day under the PR schedule.

After redetermination of the cocaine dose-effect curve, the effects of chronic mecamylamine $\mathrm{HCl}$ treatment were examined in a man- ner similar to varenicline. Treatment was initiated with $0.3 \mathrm{mg} / \mathrm{kg}$ p.o. at 7:30 $\mathrm{AM}$ and 4:30 PM, and a cocaine self-administration session was conducted on day 7 of treatment. If a lack of effect was observed, the mecamylamine dose was raised in quarter- or half-log increments up to $1.7 \mathrm{mg} / \mathrm{kg}$ p.o. b.i.d. If this dose was found to be ineffective in altering cocaine self-administration, the route of administration was changed first to intramuscular injection, then to intravenous administration, in an effort to maximize potential behavioral effects without drawing on dose ranges outside of a therapeutic window. For example, $1.7 \mathrm{mg} / \mathrm{kg}$ mecamylamine has been shown to produce behavioral effects when administered intramuscularly. (e.g., Katner et al., 2004). When administered intravenously, mecamylamine was flushed directly through the intravenous access catheter with $3 \mathrm{ml}$ of saline; afternoon doses were infused at 2:30 PM so as not to disrupt self-administration probe sessions.

\section{Cocaine Discrimination}

Procedure. Monkeys R-1524, R-1525, and R-1430 had previously been trained to discriminate response-contingent intravenous cocaine from saline (Martelle and Nader, 2009). For the present studies, each monkey was trained to discriminate $0.3 \mathrm{mg} / \mathrm{kg}$ cocaine from saline. In brief, before each session the catheter was filled with saline or $0.3 \mathrm{mg} / \mathrm{kg}$ cocaine. Each session began with the illumination of a yellow light over the centrally located switch. Completion of an FR 50 (R-1430 and R-1524) or FR 100 (R-1525) resulted in extinction of the yellow light and simultaneous illumination of the red lights above both levers for $10 \mathrm{~s}$, during which the stimulus to be discriminated (cocaine or saline) was infused over $10 \mathrm{~s}$. This infusion was followed by a 15-min timeout during which all lights were extinguished, and responding across all manipulanda had no consequence. After the timeout, the discrimination component began, signaled by illumination of the white stimulus lights above each lever. Completion of the FR on the injection-appropriate lever resulted in delivery of a 1-g pellet; responding on the opposite lever was not reinforced and reset the response requirement on the correct lever. Training occurred under a CCSSCSSCCS (C, cocaine; S, saline) schedule 5 to 7 days per week. Cocaine- and saline-associated levers were counterbalanced across monkeys. Once each monkey reliably acquired the discrimination (5 consecutive days on which the first fixed-ratio was completed on the correct lever and $>80 \%$ of total responses were emitted on the drug-appropriate lever), test (T) sessions were implemented following a CSTSCT schedule. Test sessions were conducted only if criteria were met for responding in the previous $\mathrm{C}$ and $\mathrm{S}$ training sessions. Test sessions were identical to training sessions except that completion of an FR on either lever resulted in pellet delivery. Sessions lasted $45 \mathrm{~min}$ or until all 10 pellets had been received, whichever came first. Thirty minutes after the completion of the discrimination component (training or test session), a 30-s infusion of heparinized saline $(100 \mathrm{U} / \mathrm{ml})$ was delivered via a second infusion pump to maintain catheter patency and expel any residual drug in the catheter.

Experiment 3: Effects of nAChR Compounds on Cocaine Discrimination. Varenicline $(0.1$ and $0.3 \mathrm{mg} / \mathrm{kg}$, salt $)$ and mecamylamine $(0.3-1.7 \mathrm{mg} / \mathrm{kg}$, salt) were administered noncontingently $1 \mathrm{~h}$ before monkeys self-administered the dose of cocaine or saline to be discriminated; nicotine $(0.03$ and $0.1 \mathrm{mg} / \mathrm{kg}$, base) was administered $15 \mathrm{~min}$ before the start of the session. Haloperidol $(0.003-0.03 \mathrm{mg} /$ $\mathrm{kg}$ ) was tested in combination with the training dose of cocaine and was administered intravenously 5 min before the start of the session. Order of testing for all monkeys was as follows: varenicline, nicotine, mecamylamine, haloperidol. Before testing another drug and after completion of all studies, the discriminative stimulus effects of selected doses of cocaine were re-evaluated to confirm that the shape of the cocaine dose-response curve was not altered.

\section{Data Analysis}

For the self-administration studies, the primary dependent variable was the number of injections received. For self-administration 
dose-response curves (experiment 1), data were analyzed using a one-way analysis of variance (ANOVA) using 3-day means for each substituted dose. Post hoc Holm-Sidak $t$ tests compared the number of injections received for each dose to the number of injections of saline received. Drug doses were considered reinforcing if the 3-day mean was significantly higher than the average number of injections received when saline was available, with significance accepted when $p<0.05$.

For experiment 2, individual differences in dose sensitivity of the treatments precluded group statistics. To examine the effects of chronic treatment on cocaine self-administration, two-way ANOVAs were conducted for each individual monkey using treatment dose (varenicline or mecamylamine) and cocaine dose as factors. Additional one-way ANOVAs were conducted for each monkey examining the percentage of total food pellets earned in the first $2 \mathrm{~h}$ of availability. For this analysis, sessions were divided into weekly bins of seven sessions each (corresponding with the minimum 7-day treatment per dose). Post hoc Holm-Sidak tests were used to compare specific doses between treatment conditions and the average weekly percentage of food pellets earned to baseline levels when a main effect was observed. For mecamylamine treatment, because doses delivered via various routes produced similar reductions in foodmaintained responding without altering the reinforcing strength of cocaine, data were pooled across routes of administration and a two-way ANOVA was conducted using mecamylamine dose and cocaine dose as factors. Because treatment durations were shorter than chronic varenicline treatments, food-maintained responding could not be separated into weekly bins for statistical comparison across weeks of treatment.

For cocaine discrimination data (experiment 3), the primary dependent variables were percentage of cocaine-appropriate responding and response rates (responses per second). The discriminative stimulus effects of cocaine (in the absence of drug pretreatment) did not change throughout the duration of the study, so mean cocaine dose-response curve data were used for all treatment drugs. Doses of drugs or drug combinations with the training dose that resulted in $<50 \%$ cocaine-appropriate responding were considered significantly different from the training dose effects. Doses of drugs or drug combinations with any dose of cocaine that resulted in 50 to $80 \%$ cocaine-appropriate responding were considered to partially substitute for cocaine. Doses of drugs or drug combinations that resulted in $>80 \%$ cocaine-appropriate responding were considered to fully substitute for the cocaine discriminative stimulus. In addition, $\mathrm{ED}_{50}$ values (interpolated doses that resulted in 50\% cocaine-appropriate lever responding) were generated for monkeys R-1430 and R-1524 for each treatment and dose. $\mathrm{ED}_{50}$ values could not be calculated for monkey $\mathrm{R}-1525$ because pretreatment with nicotine, varenicline, and mecamylamine all engendered $>50 \%$ cocaine-appropriate responding when administered before the lowest dose of cocaine tested.

\section{Drugs}

(-)Cocaine HCl (National Institute on Drug Abuse, Bethesda, MD) was dissolved in sterile $0.9 \%$ saline. Varenicline (National Institute on Drug Abuse, RTI, Durham, NC), nicotine bitartrate (SigmaAldrich, St. Louis, MO), and mecamylamine HCl (US Pharmacopeia, Rockville, MD) were dissolved in sterile saline. Sodium hydroxide was added to varenicline and nicotine to reach a stable $\mathrm{pH}$ range of 5 to 8 . For drug self-administration studies, different doses were studied by changing the concentration of drug available. Haloperidol (McNeil Pharmaceuticals, Raritan, NJ) was dissolved in sterile saline immediately before testing.

\section{Results}

\section{Self-Administration}

Experiment 1: Assessment of the Reinforcing Effects of Varenicline and Nicotine. When substituted for the training dose, cocaine dose-dependently increased the number of injections self-administered under a PR schedule $\left(F_{5,9}=10.55 ; p<0.005\right)$ with all cocaine doses except 0.01 $\mathrm{mg} / \mathrm{kg}$ resulting in significantly higher numbers of injections compared with when saline was available (all $p<0.05$; Fig. 1). When substituted for the baseline dose of cocaine, no dose of varenicline or nicotine resulted in significantly higher number of injections compared with when saline was available (Fig. 1).

Experiment 2: Effects of Chronic Varenicline and Mecamylamine Treatment on Cocaine- and FoodMaintained Responding. Effects of varenicline on cocaine self-administration. For R-1425, R-1429 and R-1526, the number of self-administered cocaine injections varied significantly as a function of dose $\left(F_{5,25}=55.62, F_{6,28}=51.71\right.$, and $F_{6,29}=65.91$, respectively; all $p<0.001$; Fig. 2 A-C). After varenicline treatment (Fig. 2), there was a significant main effect of varenicline dose $\left(F_{2,25}=13.77\right.$ and $F_{2,29}=14.80$; both at $p<0.001$ in R-1425 and R-1526) and/or a significant interaction $\left(F_{12,28}=4.49\right.$ and $F_{12,29}=2.16 ; p<0.05$ in R-1429 and R-1526) on number of cocaine injections. Low doses of varenicline $(0.03$ and $0.1 \mathrm{mg} / \mathrm{kg})$ did not alter the number of self-administered cocaine injections. Post hoc analysis for data from R-1425 revealed that treatment with both 0.3 and $0.56 \mathrm{mg} / \mathrm{kg}$ b.i.d. varenicline resulted in significant increases in the number of cocaine injections when 0.01 and $0.56 \mathrm{mg} / \mathrm{kg}$ cocaine were available compared with baseline ( $p<0.001$; Fig. 2A). In R-1429, post hoc testing indicated that 0.3 and $0.56 \mathrm{mg} / \mathrm{kg}$ b.i.d. varenicline resulted in significant increases in numbers of injections from the baseline cocaine dose-response curve when $0.003 \mathrm{mg} / \mathrm{kg}$ and significant decreases when $0.1 \mathrm{mg} / \mathrm{kg}$ cocaine was available (all $p<$ 0.05; Fig. 2B). In R-1526, posthoc tests indicated that 0.3 $\mathrm{mg} / \mathrm{kg}$ b.i.d. varenicline treatment resulted in significant increases in the number of injections from the baseline cocaine dose-response curve when saline and $0.003 \mathrm{mg} / \mathrm{kg}$ cocaine were available $(p<0.05)$, whereas $0.56 \mathrm{mg} / \mathrm{kg}$ b.i.d. varenicline treatment resulted in significant increases in the number of $0.56 \mathrm{mg} / \mathrm{kg}$ cocaine injections received $(p<0.001$; Fig. 2C).

Effects of varenicline on food-maintained responding. Under baseline conditions, R-1425 and R-1429 earned all of their food allotment within approximately $2 \mathrm{~h}$ by responding under an FR schedule (Fig. 2, D and E). In those two mon-

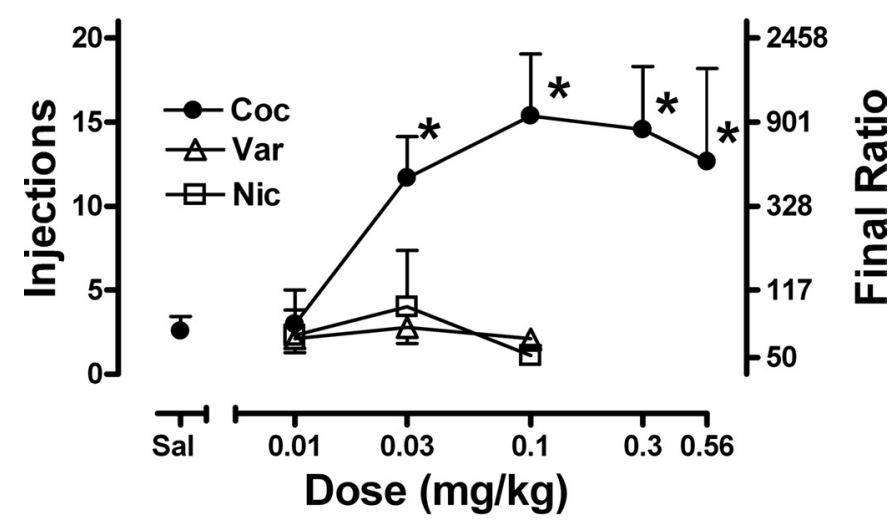

Fig. 1. Mean ( \pm S.E.M.) number of injections of self-administered cocaine (Coc), varenicline (Var), or nicotine (Nic). Data are the means of the last three sessions of availability in three monkeys (except $0.03 \mathrm{mg} / \mathrm{kg}$ cocaine; $n=2$ ). $*$, significantly different from saline (Sal), $p<0.05$. 

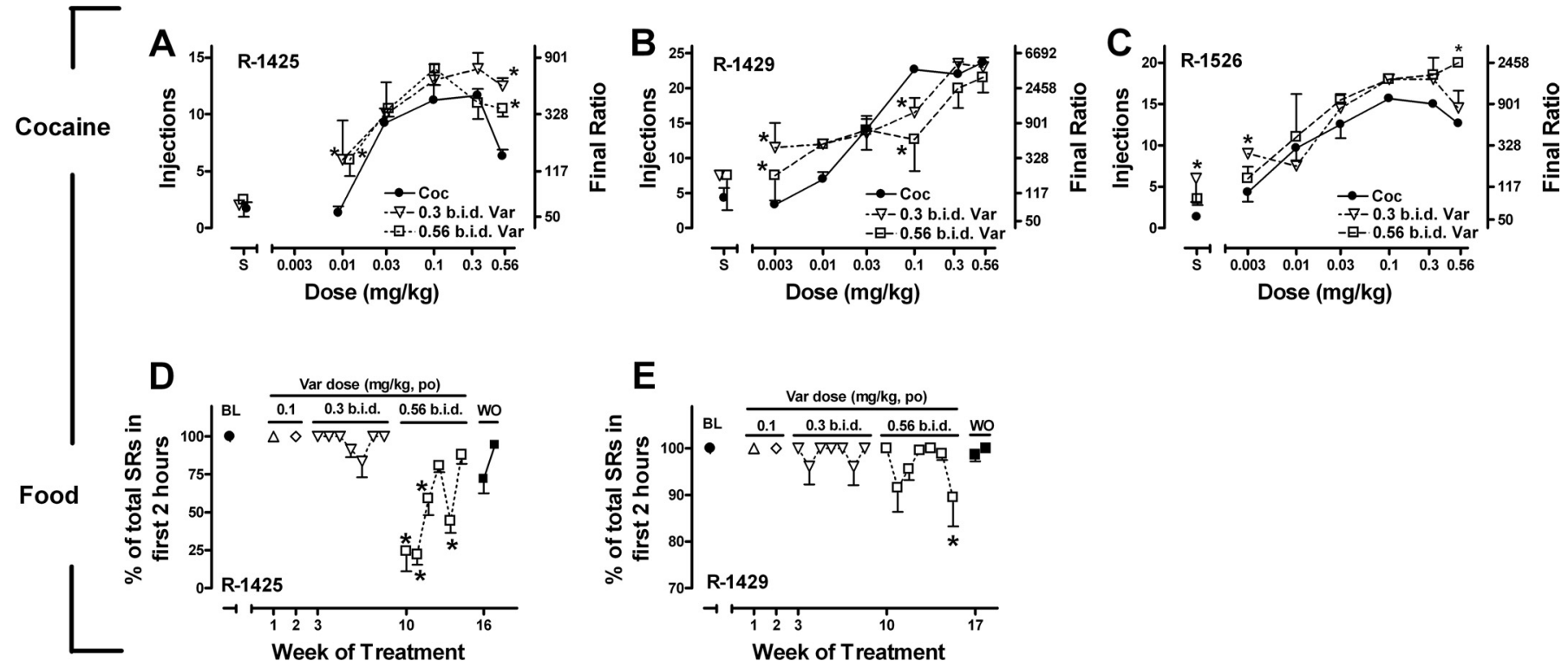

Fig. 2. Effects of varenicline (Var) on cocaine (Coc) and food self-administration. A-C, mean \pm S.E.M. number of cocaine injections received in three monkeys. D and E, percentage of total daily food reinforcers (SRs) earned during the first $2 \mathrm{~h}$ of availability in weekly bins. *, significantly different from baseline (BL). For food-maintained responding, $\triangle$ represents $0.1 \mathrm{mg} / \mathrm{kg}$ once-daily varenicline, and $\diamond$ represents $0.1 \mathrm{mg} / \mathrm{kg}$ b.i.d. varenicline. WO, washout; S, saline.

keys, cocaine reinforcement in the afternoon sessions did not influence the number of pellets or the time to obtain all food reinforcement on subsequent days (e.g., all pellets were received within the first $2 \mathrm{~h}$ of the session; food-maintained responding was not studied in R-1526). In R-1425, there was a significant effect of treatment on the percentage of pellets received within $2 \mathrm{~h}$ when examined in weekly bins $\left(F_{23,135}=\right.$ 13.97; $p<0.001$ ) such that weeks $10,11,12$, and 14 were significantly lower than baseline $(p<0.001$; Fig. 2D). On days 2 to 14 of $0.56 \mathrm{mg} / \mathrm{kg}$ varenicline treatment, the number of food reinforcers earned averaged less than half the total number of reinforcers allotted. Tolerance to the rate-decreasing effect of $0.56 \mathrm{mg} / \mathrm{kg}$ varenicline was apparent by day 15 such that all reinforcers were earned within the allotted time period (data not shown). In R-1429, there was a significant effect of varenicline dose on the percentage of pellets received within the first $2 \mathrm{~h}$ when examined in weekly bins $\left(F_{24,144}=\right.$ $1.79 ; p<0.05)$ such that week 16 was significantly different from baseline ( $p<0.05$; Fig. $2 \mathrm{E})$. All pellets were still earned within the 23-h time period.

Effects of mecamylamine on cocaine self-administration and food-maintained responding. In contrast to the effects of varenicline, no dose of mecamylamine regardless of route of administration altered the baseline cocaine dose-response curve, so data were combined across routes to compare across cocaine doses (Fig. 3, A-C). At the highest dose tested (1.7

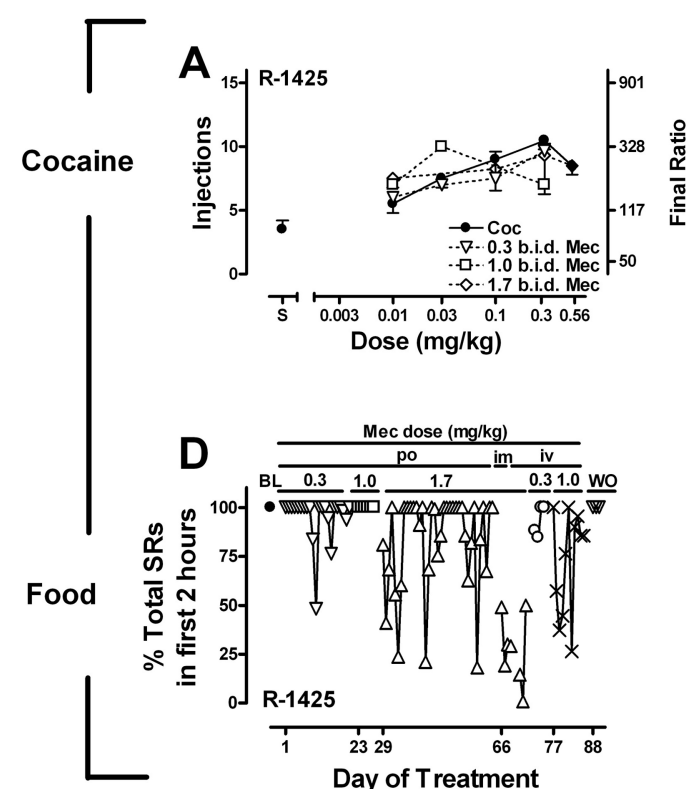

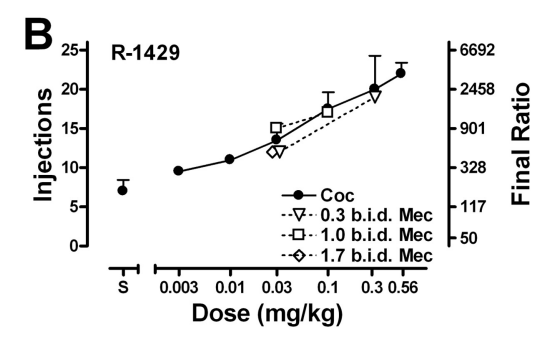
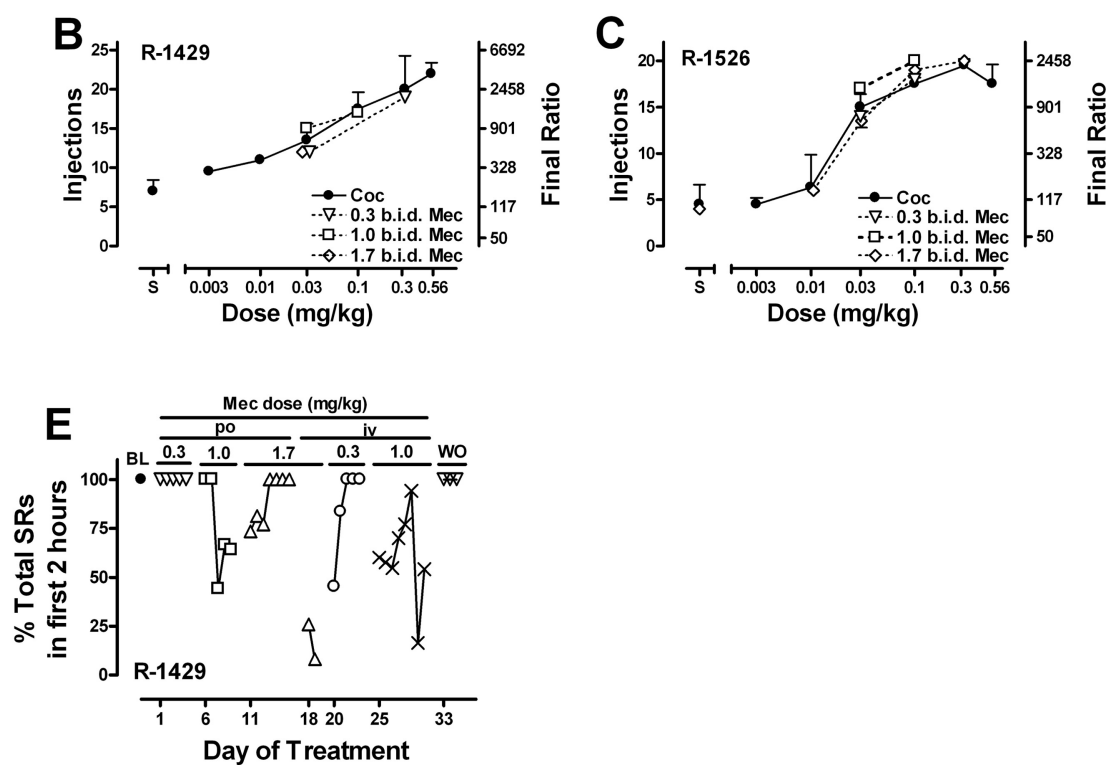

Fig. 3. Effects of mecamylamine (Mec) on cocaine $(\mathrm{Coc})$ and food self-administration. A-C, mean \pm S.E.M. number of cocaine injections received in three monkeys. D and E, percentage of total daily food reinforcers (SRs) earned during the first $2 \mathrm{~h}$ of availability each day of treatment. BL, baseline; WO, washout; S, saline. Points without error bars were not double-determined. 
$\mathrm{mg} / \mathrm{kg}$ mecamylamine b.i.d.), food-maintained responding was reduced $>50 \%$ when administered intramuscularly or intravenously, but not orally (Fig. 3, D and E). Although both monkeys showed reduced rates of food-maintained responding, only R-1425 failed to earn all food pellets, and this only occurred on 6 of 48 days during $1.7 \mathrm{mg} / \mathrm{kg}$ mecamylamine treatment (not shown).

\section{Cocaine Discrimination}

Experiment 3: Effects of nAChR Compounds on Cocaine Discrimination. In all monkeys, cocaine engendered dose-dependent increases in cocaine-appropriate responding with approximately $100 \%$ response allocation on the cocaineassociated lever when the training dose was available (Fig. 4, filled symbols). Mean rates of responding were $1.49 \pm 0.44$ and $1.40 \pm 0.52 \mathrm{responses} / \mathrm{sec}$ after saline and $0.3 \mathrm{mg} / \mathrm{kg}$ cocaine, respectively; these response rates were not significantly different. Nicotine partially substituted for the cocaine stimulus in one of three monkeys (R-1525; Fig. 4, top, points above $\mathrm{S}$ ). In all three monkeys, $0.1 \mathrm{mg} / \mathrm{kg}$ nicotine pretreat- ment significantly increased cocaine-appropriate responding when combined with low doses of cocaine. In R-1525, a lower dose of nicotine $(0.03 \mathrm{mg} / \mathrm{kg})$ increased the percentage of cocaine-appropriate responding when combined with 0.01 $\mathrm{mg} / \mathrm{kg}$ cocaine, but decreased cocaine-like responding when combined with $0.1 \mathrm{mg} / \mathrm{kg}$ cocaine. A higher nicotine dose $(0.1$ $\mathrm{mg} / \mathrm{kg}$ ) only increased the percentage of cocaine-appropriate responding for 0.01 and $0.03 \mathrm{mg} / \mathrm{kg}$ cocaine (Fig. 4, top right). In both R-1430 and R-1524, $0.1 \mathrm{mg} / \mathrm{kg}$ nicotine shifted the $\mathrm{ED}_{50}$ from 0.10 and $0.12 \mathrm{mg} / \mathrm{kg}$, respectively, to $0.02 \mathrm{mg} / \mathrm{kg}$. There were no significant effects of nicotine on response rates (data not shown).

In $\mathrm{R}-1430,0.1 \mathrm{mg} / \mathrm{kg}$ varenicline alone occasioned nearly $50 \%$ cocaine-appropriate responding, indicating partial substitution (Fig. 4, middle left, data above S). Varenicline pretreatment also increased cocaine-appropriate responding when combined with low cocaine doses in all three monkeys. For two monkeys, $0.3 \mathrm{mg} / \mathrm{kg}$ varenicline increased cocaineappropriate responding at two doses, which caused a left-

\section{Nicotine}
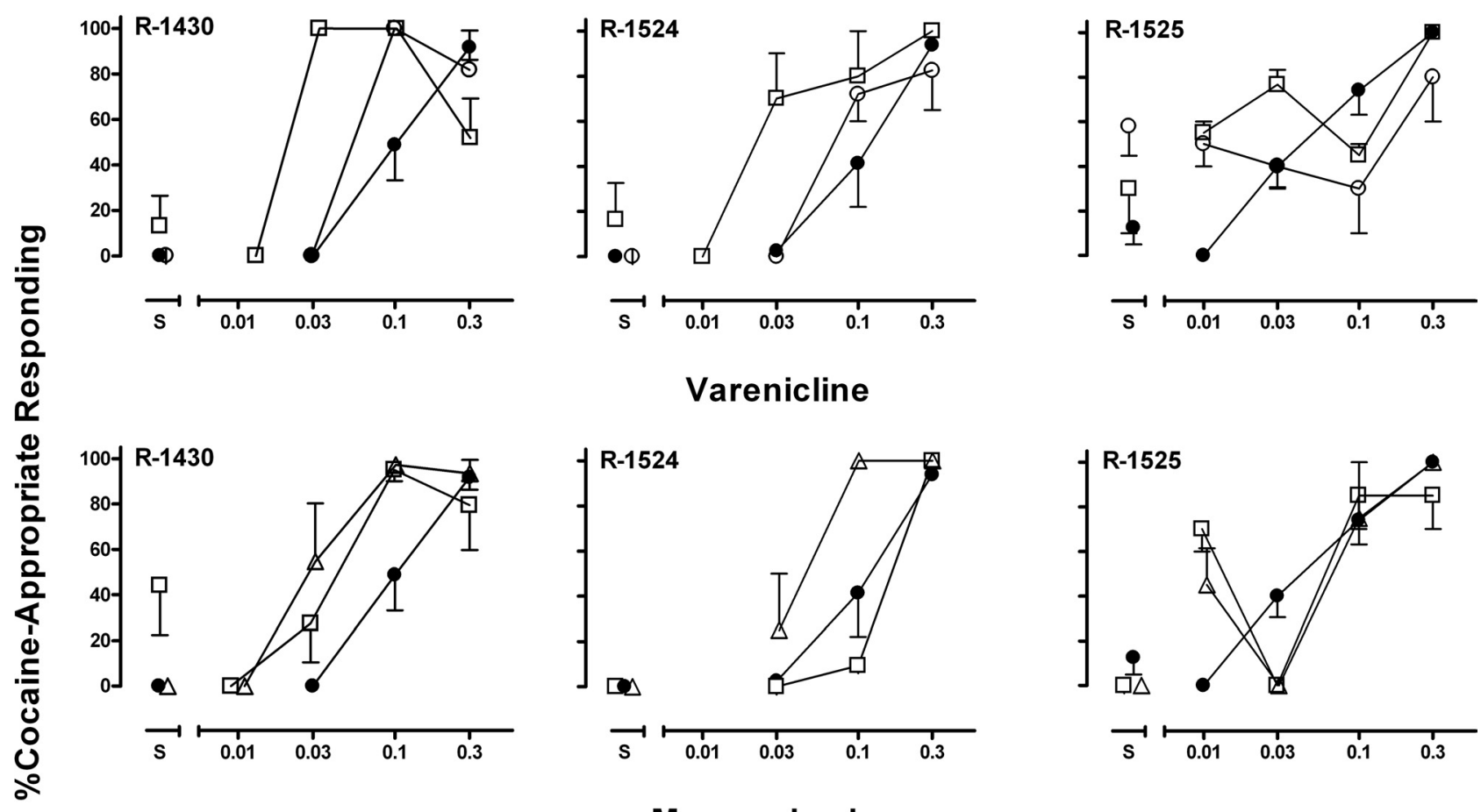

\section{Mecamylamine}
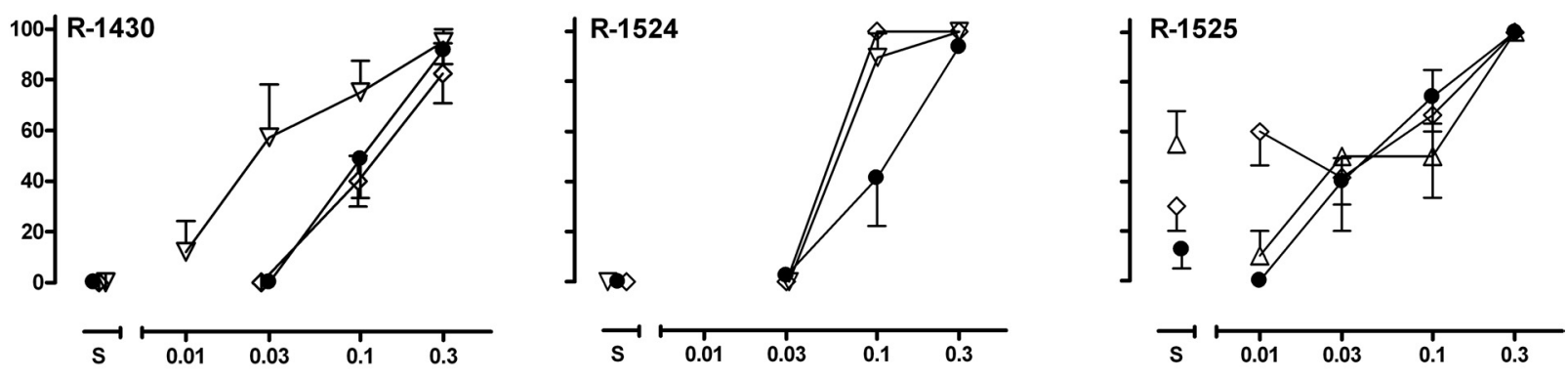

Cocaine (mg/kg, i.v.)

Fig. 4. Effects of nicotine (top), varenicline (middle), and mecamylamine (bottom) on the discriminative stimulus effects of cocaine. Different symbols represent different doses: $\bullet$, cocaine alone; $\bigcirc,+0.03 \mathrm{mg} / \mathrm{kg} ; \square,+0.1 \mathrm{mg} / \mathrm{kg} ; \triangle,+0.3 \mathrm{mg} / \mathrm{kg} ; \diamond,+1.0 \mathrm{mg} / \mathrm{kg} ; \nabla,+1.7 \mathrm{mg} / \mathrm{kg}$. S, saline. 
ward shift in the cocaine dose-response curve. For R-1525, varenicline pretreatment increased cocaine-appropriate responding when combined with $0.01 \mathrm{mg} / \mathrm{kg}$ cocaine, which, when tested alone, occasioned $0 \%$ cocaine-lever responding (Fig. 4, middle right). In R-1430 and R-1524, $0.3 \mathrm{mg} / \mathrm{kg}$ varenicline shifted the $\mathrm{ED}_{50}$ from 0.10 and 0.12 to 0.03 and 0.05 $\mathrm{mg} / \mathrm{kg}$, respectively. There were no significant effects of varenicline on response rates (data not shown).

As was seen with nicotine, mecamylamine $(0.3 \mathrm{mg} / \mathrm{kg})$ alone partially substituted for the cocaine stimulus in $\mathrm{R}-1525$. Mecamylamine pretreatment significantly increased cocaine-appropriate responding when combined with low cocaine doses (Fig. 4, bottom). For R-1430 this occurred after the highest dose of mecamylamine $(1.7 \mathrm{mg} / \mathrm{kg})$, which shifted the cocaine dose-response curve to the left. For R-1524 and $\mathrm{R}-1525$, mecamylamine pretreatments increased cocaine-appropriate responding after one dose of cocaine. In R-1430 and $\mathrm{R}-1524,1.7 \mathrm{mg} / \mathrm{kg}$ mecamylamine shifted the $\mathrm{ED}_{50}$ from 0.10 and 0.12 to 0.03 and $0.06 \mathrm{mg} / \mathrm{kg}$, respectively. There were no significant effects of mecamylamine on response rates (data not shown). As a positive control, haloperidol was tested with the training dose of cocaine and decreased percent cocaineappropriate responding by $>50 \%$ in all three monkeys; in two monkeys, haloperidol also decreased response rates (Table 1).

\section{Discussion}

The effects of varenicline, a low-efficacy $\alpha 4 \beta 2 *$ subtypeselective nicotinic acetylcholine receptor agonist, the nonselective high-efficacy agonist nicotine, and the nonselective antagonist mecamylamine were evaluated for their ability to influence the reinforcing strength and discriminative stimulus effects of cocaine in nonhuman primates. In contrast to our hypothesis, chronic administration of varenicline increased the reinforcing strength of cocaine in all monkeys tested; varenicline also decreased food-maintained responding, but tolerance developed to that effect. In contrast to the potentiation in cocaine self-administration by varenicline, chronic mecamylamine did not significantly affect cocaine break points, but did decrease food-maintained responding. When substituted for cocaine using a PR schedule, neither varenicline nor nicotine maintained responding above levels observed when saline was available, consistent with low abuse potential in humans (McColl et al., 2008). Likewise, neither varenicline nor nicotine fully substituted for cocaine in monkeys trained to discriminate cocaine from saline. Whereas chronic varenicline increased cocaine self-administration, acute administration of varenicline potentiated the discriminative stimulus effects of cocaine, as did acute administration of nicotine and mecamylamine. Overall, the abuse liability of varenicline in monkey models of cocaine abuse seems minimal, but the ability of varenicline to potentiate the reinforcing and discriminative-stimulus effects of cocaine suggests that varenicline would not be an effective pharmacotherapy for cocaine dependence.

Other investigators have shown that varenicline can have reinforcing effects (e.g., Rollema et al., 2007). However, in monkeys trained to self-administer cocaine under a PR schedule, breakpoints and number of injections of varenicline were not different from saline, indicating that varenicline did not function as a reinforcer under these conditions. One caveat to these findings is that nicotine also did not result in breakpoints or number of injections that were significantly different from saline, suggesting the PR contingencies used in this study may have been too demanding to show the reinforcing effects of full and partial nicotine agonists. The infusion rate, one factor that is deemed important in establishing intravenous nicotine self-administration in animals (see Freeman and Woolverton, 2009), was identical to the rate of delivery $(10 \mathrm{~s})$ in studies where nicotine was reinforcing (albeit a weak reinforcer) under a PR schedule in rhesus monkeys (Freeman and Woolverton, 2009). In monkeys trained to discriminate cocaine, varenicline, nicotine, and mecamylamine all showed partial substitution in one of three monkeys. The lack of robust substitution after nicotine is at odds with other monkey studies (Garza and Johanson, 1983) and rodent studies (Desai et al., 2003). One possible reason for the lack of cocaine-like discriminative stimulus effects may be a methodological consideration in the present drug discrimination paradigm. As described previously (Martelle and Nader, 2009), these monkeys self-administered the stimulus that was evaluated in drug discrimination. It may be that the discriminative stimulus effects of self-administered drugs, while having greater face validity than noncontingent drug administration, yield different substitution profiles. In addition, the route of drug pretreatment precluded testing higher doses that may have engendered greater substitution. Although additional research is needed using this model, the data from the cocaine discrimination and cocaine self-administration studies reported here suggest that varenicline has low abuse potential.

The ability of varenicline to potentiate rather than attenuate the reinforcing strength of cocaine resembles the effects of acute nicotine (Freeman and Woolverton, 2009) and direct DA agonists (Rowlett et al., 2007) on cocaine self-administra-

TABLE 1

Effects of haloperidol on the discriminative stimulus effects of cocaine $(0.3 \mathrm{mg} / \mathrm{kg}$, i.v. $)$

\begin{tabular}{|c|c|c|c|c|c|c|}
\hline & \multicolumn{2}{|c|}{$\mathrm{R}-1430$} & \multicolumn{2}{|c|}{$\mathrm{R}-1524$} & \multicolumn{2}{|c|}{ R-1525 } \\
\hline & $\begin{array}{l}\text { Cocaine Response } \\
( \pm \text { S.D. })\end{array}$ & $\begin{array}{l}\text { Response Rate } \\
( \pm \text { S.D. })\end{array}$ & $\begin{array}{l}\text { Cocaine Response } \\
( \pm \text { S.D. })\end{array}$ & $\begin{array}{l}\text { Response Rate } \\
( \pm \text { S.D. })\end{array}$ & $\begin{array}{l}\text { Cocaine Response } \\
( \pm \text { S.D. })\end{array}$ & $\begin{array}{c}\text { Response Rate } \\
( \pm \text { S.D. })\end{array}$ \\
\hline & $\%$ & & $\%$ & & $\%$ & \\
\hline Cocaine & $99.94(0.11)$ & $2.09(0.07)$ & $96.91(5.34)$ & $2.20(0.22)$ & $100(0.00)$ & $0.47(0.04)$ \\
\hline Cocaine $+0.003 \mathrm{mg} / \mathrm{kg}$ haloperidol & $75.00(7.07)$ & $1.99(0.06)$ & $59.7(56.14)$ & $2.28(0.01)$ & $100^{a}$ & $0.51^{a}$ \\
\hline Cocaine $+0.0056 \mathrm{mg} / \mathrm{kg}$ haloperidol & N.T. & N.T. & $12.7(10.32)$ & $2.17(0.10)$ & $90(14.14)$ & $0.66(0.51)$ \\
\hline Cocaine $+0.01 \mathrm{mg} / \mathrm{kg}$ haloperidol & $86.67(21.21)$ & $1.91(0.01)$ & N.T. & N.T. & $40^{a}$ & $0.07(0.1)$ \\
\hline Cocaine $+0.017 \mathrm{mg} / \mathrm{kg}$ haloperidol & $90.2(11.74)$ & $0.1 \quad(0.08)$ & N.T. & N.T. & N.T. & N.T. \\
\hline Cocaine $+0.03 \mathrm{mg} / \mathrm{kg}$ haloperidol & $43.5^{a}$ & $0.81(1.15)$ & N.T. & N.T. & N.T. & N.T. \\
\hline
\end{tabular}

Each point is the mean ( \pm S.D.) of two determinations except where noted $\left(^{a}\right)$.

N.T., not tested. 
tion under PR schedules of reinforcement in monkeys. This enhancement of cocaine self-administration is opposite to the effects seen when chronic D-amphetamine, a DA transporter blocker/DA releaser was administered under similar conditions in monkeys (e.g., Negus and Mello, 2003; Czoty et al., 2011). It is noteworthy that varenicline increased breakpoints at both the ascending and descending limbs of the curve, an effect that may be unique to partial agonists in that agonist- and antagonist-like effects may occur at different points of the dose-response curve based on endogenous neurotransmitter activity.

Evidence has suggested that blockade of both $\alpha 4 \beta 2^{*}$ and $\alpha 7^{*}$ nAChR subtypes may be necessary to reduce cocainerelated behaviors (Zanetti et al., 2006). However, in the present study, chronic administration of the nonselective nAChR antagonist mecamylamine did not attenuate the reinforcing strength of cocaine. These data are consistent with previous results in nonhuman primates in which acute mecamylamine did not affect cocaine-maintained responding (Spealman and Goldberg, 1982) but contrast with the results of rodent studies (e.g., Levin et al., 2000). Such discrepancies may be caused by species differences in receptor subtype distribution or density (Han et al., 2000; Quik et al., 2000), schedules of reinforcement used, or drug history of the subjects. The animals in the current study had an extensive cocaine selfadministration history. In addition, mecamylamine was administered chronically in this study (up to 80 consecutive days) in which access to cocaine was studied intermittently. A growing literature describes the important implications of dosing regimen for $\mathrm{nAChR}$ compounds including acute versus chronic treatment, use of minipump administration, or frequent, repeated dosing (current study) versus once-daily injections (e.g., Levin et al., 2000), and the effects of each regimen on receptor activation versus desensitization (see Matta et al., 2007; Picciotto et al., 2008 for reviews).

Varenicline and mecamylamine administration resulted in dose-dependent reductions in food-maintained responding under an FR schedule. Our dose escalation procedure modeled a titration regimen prescribed for varenicline for smoking cessation to minimize unwanted side effects. Humans taking varenicline or mecamylamine report constipation, taste perversion, and nausea attributed to parasympathetic system inhibition (see Young et al., 2001; Gonzales et al., 2006). All monkeys readily ingested supplemental fruit and enrichment between sessions, suggesting that the rate-decreasing effects on food-maintained responding, whether centrally or peripherally mediated, were not the result of anorexia or satiation. Regardless, tolerance developed to the rate-decreasing effects of both varenicline and mecamylamine (Figs. 2 and 3, D and E). No unconditioned behavioral effects of chronic oral varenicline were noted. In addition, our implementation of intermittent access to cocaine self-administration models chronic drug treatment followed by lapses in abstinence often observed in human drug users (see Czoty et al., 2011 for discussion).

Acute varenicline pretreatment potentiated the discriminative stimulus effects of cocaine. In two of three monkeys, varenicline, nicotine, and mecamylamine shifted the cocaine dose-response curve upward or leftward. The behavioral effects of all three nAChR agents resembled the effects of direct and indirect DA agonists (for review see Callahan et al., 1997) in that they potentiated the discriminative stimulus effects of cocaine, supporting the hypothesis that the current findings are a result of $\mathrm{nAChR}$-mediated DA release (Desai et al., 2003; Rollema et al., 2007, 2010). As a positive control, the DA D2-like receptor antagonist haloperidol attenuated the discriminative stimulus effects of cocaine in all three monkeys. It is possible that higher doses of varenicline or mecamylamine would have decreased cocaine-appropriate responding. However, although there were no effects of these drugs on response rates, higher doses were not tested because intravenous administration produced unwanted side effects (nicotine and varenicline: hypersalivation, panting, pupil dilation, flushing of the face, or scratching that subsided within 1 min of administration; mecamylamine: sedative effect lasting several hours).

Previous studies in rats have shown that mecamylamine does not alter the discriminative stimulus effects of cocaine (Desai et al., 2003). Unexpectedly, the current results showed that mecamylamine potentiated the discriminative stimulus effects of cocaine in all three monkeys tested. Such discrepancies may be caused by species-specific receptor distribution, route of administration, pretreatment time, or drug history. An ongoing focus regarding nAChR-mediated effects is the uncertain behavioral consequences of receptor activation versus desensitization. In vitro studies showed that both activation and desensitization of $\alpha 4 \beta 2 *$ receptors resulted in $\mathrm{nAChR}$-mediated DA release (for review see Picciotto et al., 2008). Furthermore, nicotine and varenicline can both activate and desensitize $\alpha 4 \beta 2 * \mathrm{nAChRs}$ in a brain region-specific manner depending on dose and duration of administration (Rollema et al., 2010). In theory, receptor desensitization may produce similar behavioral effects to functional antagonism (for review see Picciotto et al., 2008). Similar effects of nicotine and mecamylamine on measures of monoaminergic release (Kenny et al., 2000) and cognition (for review see Young et al., 2001) have also been documented.

In the present study, varenicline increased the reinforcing strength and discriminative stimulus effects of cocaine similar to the effects of the full agonist nicotine in monkeys (Freeman and Woolverton, 2009), suggesting that even low efficacy at $\alpha 4 \beta 2 *$ nAChRs may stimulate DA release sufficiently to potentiate the reinforcing strength and discriminative stimulus effects of cocaine. Alternatively, varenicline is a high-efficacy agonist with low affinity for $\alpha 7^{*}$ and $\alpha 3 \beta 4^{*}$ nAChRs (Coe et al., 2005; Mihalak et al., 2006). Administration of high doses of varenicline can activate $\alpha 7^{*} \mathrm{nAChRs}$ and simultaneously desensitize $\alpha 4 \beta 2 *$ subtype receptors in a region-specific manner (for review see Dani and Bertrand, 2007; Picciotto et al., 2008). Future studies with more selective compounds of varying efficacy for $\mathrm{nAChR}$ subtypes will help elucidate the contributions of $\alpha 4 \beta 2^{*}$ and $\alpha 7^{*} \mathrm{nAChR}$ subtypes and the importance of activation versus desensitization mediating ACh effects on DA neurons. The current behavioral data do not support the use of varenicline as a treatment for cocaine dependence.

\section{Acknowledgments}

We thank Tonya Calhoun and Michael Coller for technical assistance.

\section{Authorship Contributions \\ Participated in research design: Gould, Czoty, S. Nader, and M. Nader.}


Conducted experiments: Gould and Czoty.

Performed data analysis: Gould and Czoty.

Wrote or contributed to the writing of the manuscript: Gould, Czoty, S. Nader, and M. Nader.

\section{References}

Callahan PM, De La Garza R 2nd, and Cunningham KA (1997) Mediation of the discriminative stimulus properties of cocaine by mesocorticolimbic dopamine systems. Pharmacol Biochem Behav 57:601-607.

Coe JW, Brooks PR, Vetelino MG, Wirtz MC, Arnold EP, Huang J, Sands SB, Davis TI, Lebel LA, Fox CB, et al. (2005) Varenicline: an $\alpha 4 \beta 2$ nicotinic acetylcholine receptor partial agonist for smoking cessation. J Med Chem 48:3474-3477.

Czoty PW, Gould RW, Martelle JL, and Nader MA (2011) Prolonged attenuation of the reinforcing effects of cocaine by chronic D-amphetamine in rhesus monkeys. Neuropsychopharmacology 36:539-547.

Czoty PW, Martelle JL, and Nader MA (2006) Influence of abstinence and conditions of cocaine access on the reinforcing strength of cocaine in nonhuman primates. Drug Alcohol Depend 85:213-220.

Dani JA and Bertrand D (2007) Nicotinic acetylcholine receptors and nicotinic cholinergic mechanisms of the central nervous system. Annu Rev Pharmacol Toxicol 47:699-729.

Desai RI, Barber DJ, and Terry P (2003) Dopaminergic and cholinergic involvement in the discriminative stimulus effects of nicotine and cocaine in rats. Psychopharmacology (Berl) 167:335-343.

Desai RI and Bergman J (2010) Drug discrimination in methamphetamine-trained rats: effects of cholinergic nicotinic compounds. J Pharmacol Exp Ther 335:807816 .

Freeman KB and Woolverton WL (2009) Self-administration of cocaine and nicotine mixtures by rhesus monkeys. Psychopharmacology (Berl) 207:99-106.

Garza RD and Johanson CE (1983) The discriminative stimulus properties of cocaine in the rhesus monkey. Pharmacol Biochem Behav 19:145-148.

Gonzales D, Rennard SI, Nides M, Oncken C, Azoulay S, Billing CB, Watsky EJ, Gong J, Williams KE, Reeves KR, et al. (2006) Varenicline, an $\alpha 4 \beta 2$ nicotinic acetylcholine receptor partial agonist, vs. sustained-release bupropion and placebo for smoking cessation: a randomized controlled trial. JAMA 296:47-55.

Grabowski J, Shearer J, Merrill J, and Negus SS (2004) Agonist-like, replacement pharmacotherapy for stimulant abuse and dependence. Addict Behav 29:14391464.

Guillem K and Peoples LL (2010) Varenicline effects on cocaine self-administration and reinstatement behavior. Behav Pharmacol 21:96-103.

Han ZY, Le Novère N, Zoli M, Hill JA Jr, Champtiaux N, and Changeux JP (2000) Localization of nAChR subunit mRNAs in the brain of Macaca mulatta. Eur J Neurosci 12:3664-3674.

Institute for Laboratory Animal Research (2003) Guidelines for the Care and Use of Mammals in Neuroscience and Behavioral Research, Institute for Laboratory Animal Research, Committee on Guidelines for the Use of Animals in Neuroscience and Behavioral Research, National Research Council, Washington, DC.

Karila L, Gorelick D, Weinstein A, Noble F, Benyamina A, Coscas S, Blecha L, Lowenstein W, Martinot JL, Reynaud M, et al. (2008) New treatments for cocaine dependence: a focused review. Int $J$ Neuropsychopharmacol 11:425-438.

Katner SN, Davis SA, Kirsten AJ, and Taffe MA (2004) Effects of nicotine and mecamylamine on cognition in rhesus monkeys. Psychopharmacology (Berl) 175: $225-240$.

Kenny PJ, File SE, and Neal MJ (2000) Evidence for a complex influence of nicotinic acetylcholine receptors on hippocampal serotonin release. J Neurochem 75:24092414 .

Lester DB, Rogers TD, and Blaha CD (2010) Acetylcholine-dopamine interactions in the pathophysiology and treatment of CNS disorders. CNS Neurosci Ther 16:137162

Levin ED, Mead T, Rezvani AH, Rose JE, Gallivan C, and Gross R (2000) The nicotinic antagonist mecamylamine preferentially inhibits cocaine vs. food selfadministration in rats. Physiol Behav 71:565-570.

Martelle JL and Nader MA (2009) A within-subject assessment of the discriminative stimulus and reinforcing effects of self-administered cocaine in rhesus monkeys. Psychopharmacology (Berl) 203:343-353.

Matta SG, Balfour DJ, Benowitz NL, Boyd RT, Buccafusco JJ, Caggiula AR, Craig CR, Collins AC, Damaj MI, Donny EC, et al. (2007) Guidelines on nicotine dose selection for in vivo research. Psychopharmacology (Berl) 190:269-319.

McColl SL, Burstein AH, Reeves KR, Billing CB Jr, Stolar M, and Sellers EM (2008) Human abuse liability of the smoking cessation drug varenicline in smokers and nonsmokers. Clin Pharmacol Ther 83:607-614.
McKee SA, Harrison EL, O’Malley SS, Krishnan-Sarin S, Shi J, Tetrault JM, Picciotto MR, Petrakis IL, Estevez N, and Balchunas E (2009) Varenicline reduces alcohol self-administration in heavy-drinking smokers. Biol Psychiatry 66:185190

Mihalak KB, Carroll FI, and Luetje CW (2006) Varenicline is a partial agonist at $\alpha 4 \beta 2$ and a full agonist at $\alpha 7$ neuronal nicotinic receptors. Mol Pharmacol 70:801805 .

Negus SS and Mello NK (2003) Effects of chronic D-amphetamine treatment on cocaine- and food-maintained responding under a progressive-ratio schedule in rhesus monkeys. Psychopharmacology (Berl) 167:324-332.

Obach RS, Reed-Hagen AE, Krueger SS, Obach BJ, O'Connell TN, Zandi KS, Miller $\mathrm{S}$, and Coe JW (2006) Metabolism and disposition of varenicline, a selective $\alpha 4 \beta 2$ acetylcholine receptor partial agonist, in vivo and in vitro. Drug Metab Dispos 34:121-130.

Picciotto MR, Addy NA, Mineur YS, and Brunzell DH (2008) It is not "either/or": activation and desensitization of nicotinic acetylcholine receptors both contribute to behaviors related to nicotine addiction and mood. Prog Neurobiol 84:329-342.

Poling J, Rounsaville B, Gonsai K, Severino K, and Sofuoglu M (2010) The safety and efficacy of varenicline in cocaine using smokers maintained on methadone: a pilot study. Am J Addict 19:401-408.

Quik M, Polonskaya Y, Gillespie A, Jakowec M, Lloyd GK, and Langston JW (2000) Localization of nicotinic receptor subunit mRNAs in monkey brain by in situ hybridization. J Comp Neurol 425:58-69.

Rahman S (2011) Brain nicotinic receptors as emerging targets for drug addiction neurobiology to translational research. Prog Mol Biol Transl Sci 98:349-365.

Reid MS, Angrist B, Baker SA, O'leary S, Stone J, Schwartz M, Leiderman D, Montgomery A, Elkashef A, Majewska D, et al. (2005) A placebo controlled, double-blind study of mecamylamine treatment for cocaine dependence in patients enrolled in an opiate replacement program. Subst Abus 26:5-14.

Reid MS, Mickalian JD, Delucchi KL, and Berger SP (1999) A nicotine antagonist, mecamylamine, reduces cue-induced cocaine craving in cocaine-dependent subjects. Neuropsychopharmacology 20:297-307.

Reid MS, Mickalian JD, Delucchi KL, Hall SM, and Berger SP (1998) An acute dose of nicotine enhances cue-induced cocaine craving. Drug Alcohol Depend 49:95-104

Richardson NR and Roberts DC (1996) Progressive ratio schedules in drug selfadministration studies in rats: a method to evaluate reinforcing efficacy. $J \mathrm{Neu}$ rosci Methods 66:1-11.

Rollema H, Chambers LK, Coe JW, Glowa J, Hurst RS, Lebel LA, Lu Y, Mansbach RS, Mather RJ, Rovetti CC, et al. (2007) Pharmacological profile of the $\alpha 4 \beta 2$ nicotinic acetylcholine receptor partial agonist varenicline, an effective smoking cessation aid. Neuropharmacology 52:985-994.

Rollema H, Shrikhande A, Ward KM, Tingley FD 3rd, Coe JW, O'Neill BT, Tseng E, Wang EQ, Mather RJ, Hurst RS, et al. (2010) Pre-clinical properties of the $\alpha 4 \beta 2$ nicotinic acetylcholine receptor partial agonists varenicline, cytisine and dianicline translate to clinical efficacy for nicotine dependence. $\mathrm{Br} J$ Pharmacol 160: $334-345$.

Rose JE, Behm FM, Westman EC, Levin ED, Stein RM, and Ripka GV (1994) Mecamylamine combined with nicotine skin patch facilitates smoking cessation beyond nicotine patch treatment alone. Clin Pharmacol Ther 56:86-99.

Rowlett JK, Platt DM, Yao WD, and Spealman RD (2007) Modulation of heroin and cocaine self-administration by dopamine D1- and D2-like receptor agonists in rhesus monkeys. J Pharmacol Exp Ther 321:1135-1143.

Spealman RD and Goldberg SR (1982) Maintenance of schedule-controlled behavior by intravenous injections of nicotine in squirrel monkeys. J Pharmacol Exp Ther 223:402-408

Steensland P, Simms JA, Holgate J, Richards JK, and Bartlett SE (2007) Varenicline, an $\alpha 4 \beta 2$ nicotinic acetylcholine receptor partial agonist, selectively decreases ethanol consumption and seeking. Proc Natl Acad Sci U S A 104:12518-12523.

Young JM, Shytle RD, Sanberg PR, and George TP (2001) Mecamylamine: new therapeutic uses and toxicity/risk profile. Clin Ther 23:532-565.

Zanetti L, de Kerchove D'Exaerde A, Zanardi A, Changeux JP, Picciotto MR, and Zoli $\mathrm{M}$ (2006) Inhibition of both $\alpha 7^{*}$ and $\beta 2^{*}$ nicotinic acetylcholine receptors is necessary to prevent development of sensitization to cocaine-elicited increases in extracellular dopamine levels in the ventral striatum. Psychopharmacology 187: 181-188.

Address correspondence to: Dr. Michael A. Nader, Department of Physiology and Pharmacology, Wake Forest University School of Medicine, 546 NRC, Medical Center Boulevard, Winston-Salem, NC 27157-1083. E-mail: mnader@wakehealth.edu 